\title{
NKTR-181: A Novel Mu-Opioid Analgesic with Inherently Low Abuse Potential
}

\author{
Takahiro Miyazaki, ${ }^{1}$ Irene Y. Choi, ${ }^{1}$ Werner Rubas, Neel K. Anand, Cherie Ali, Juli Evans, \\ Hema Gursahani, Marlene Hennessy, Grace Kim, Daniel McWeeney, Juergen Pfeiffer, \\ Phi Quach, David Gauvin, Timothy A. Riley, Jennifer A. Riggs, Kathleen Gogas, \\ Jonathan Zalevsky, and Stephen K. Doberstein
}

Nektar Therapeutics, San Francisco, California (T.M., I.Y.C., W.R., N.K.A., C.A., J.E., H.G., M.H., G.K., D.M., J.P., P.Q., T.A.R., J.A.R., K.G., J.Z., S.K.D.); and MPI Research, Mattawan, Michigan (D.G.)

Received June 16, 2017; accepted August 2, 2017

\section{ABSTRACT}

The increasing availability of prescription opioid analgesics for the treatment of pain has been paralleled by an epidemic of opioid misuse, diversion, and overdose. The development of abusedeterrent formulations (ADFs) of conventional opioids such as oxycodone and morphine represents an advance in the field and has had a positive but insufficient impact, as most opioids are still prescribed in highly abusable, non-ADF forms, and abusers can tamper with ADF medications to liberate the abusable opioid within. The abuse liability of mu-opioid agonists appears to be dependent on their rapid rate of entry into the central nervous system (CNS), whereas analgesic activity appears to be a function of CNS exposure alone, suggesting that a new opioid agonist with an inherently low rate of influx across the blood-brain barrier could mediate analgesia with low abuse liability, regardless of formulation or route of administration. NKTR-181 is a novel, long-acting, selective mu-opioid agonist with structural properties that reduce its rate of entry across the blood-brain barrier compared with traditional mu-opioid agonists. NKTR-181 demonstrated maximum analgesic activity comparable to that of oxycodone in hot-plate latency and acetic-acid writhing models. NKTR-181 was distinguishable from oxycodone by its reduced abuse potential in self-administration and progressive-ratio break point models, with behavioral effects similar to those of saline, as well as reduced CNS side effects as measured by the modified Irwin test. The in vitro and in vivo studies presented here demonstrate that NKTR-181 is the first selective mu-opioid agonist to combine analgesic efficacy and reduced abuse liability through the alteration of brain-entry kinetics.

\section{Introduction}

Opioid analgesics have been used for centuries and remain one of the most effective treatments for severe pain. Drugs in

This work was supported by Nektar Therapeutics (San Francisco, CA). Portions of this work were previously presented as follows:

Fishburn CS, Wong S, Tonkin L, et al. NKTR-181: A novel opioid with slowed brain entry shows low abuse liability and reduced CNS side effects. 5th Annual Frontiers of Clinical Investigation Symposium - Pain: From Bench to Bedside; October 14-16, 2010; San Diego, CA

Harrison S, Pfeiffer J, Choi I, et al. NKTR-181: A novel opioid analgesic that exhibits reduced abuse potential and maintains full analgesic activity following repeat dosing in preclinical rodent models. The American Academy of Pain Management 22nd Annual Clinical Meeting; September 20-23, 2011; Las Vegas, NV;

Webster L, Gursahani $\mathrm{H}$, Ali C, et al. A role for novel, orally available mu-opioid agonists with both centrally and peripherally mediated analgesia in the treatment of neuropathic pain. $4^{\text {th }}$ International Congress on Neuropathic Pain; May 23-26, 2013; Toronto, Canada;

Choi I, Kim G, Evans J, et al. NKTR-181, a novel mu opioid analgesic with inherently low abuse potential and efficacy in multiple preclinical models of pain. The $16^{\text {th }}$ World Congress of Pain Meeting; September 26-30, 2016; Yokohama, Japan.

${ }^{1}$ T.M. and I.Y.C. contributed equally to this work

https://doi.org/10.1124/jpet.117.243030. this class activate specific opioid receptors in the central nervous system (CNS) and the periphery, leading to antinociceptive activity in animal models and pain relief in humans (Inturrisi, 2002; Dickenson and Kieffer, 2005; Whiteside et al., 2008). However, the use of opioid analgesics for the treatment of chronic pain remains problematic because of the narrow benefit/risk profile between analgesic efficacy and undesirable CNS adverse effects, such as sedation and respiratory depression (Spetea et al., 2010). Furthermore, the euphorogenic and reinforcing effects of opioids carry with them a high risk of addiction and misuse (Melnikova, 2010). The development of a new pharmacotherapy that could take advantage of this analgesic pathway but with inherently lower abuse liability would be a major advance in the treatment of chronic pain.

There appears to be a relationship between the brain uptake rate and the abuse liability of traditional mu-opioid agonists such as oxycodone and morphine. Generally, the more rapidly a drug reaches efficacious levels in the brain to relieve pain, the more rapid is the onset of additional CNS effects experienced by the subject. This rapid onset of CNS effects can

ABBREVIATIONS: ADF, abuse-deterrent formulation; ANOVA, analysis of variance; AUC, area under the curve; $\mathrm{AUC}_{\text {inf }}$, area under the curve extrapolation to infinity; BBB, blood-brain barrier; $\mathrm{CHO}$, Chinese hamster ovary; CNS, central nervous system; IACUC, Institutional Animal Care and Use Committee; i.p., intraperitoneal; LC-MS/MS, liquid chromatography-mass spectrometry/mass spectrometry; MOR, mu-opioid receptor; NKTR-181, $(5 \alpha, 6 \alpha)$-4,5-epoxy-6-(3,6,9,12,15,18-hexaoxanonadec-1-yloxy)-3-methoxy-17-methylmorphinan-14-ol; P-gp, P-glycoprotein; PK, pharmacokinetics. 
produce a feeling of euphoria and a concomitant increase in drug likability, reinforcing behavior, and abuse liability (Farré and Camí, 1991; Abreu et al., 2001; Marsch et al., 2001; Comer et al., 2009; Webster et al., 2012; Webster and Smith, 2015).

Because the rate of mu-opioid receptor (MOR) occupancy by $\mathrm{mu}$ agonists depends on the rate at which these compounds cross the blood-brain barrier (BBB), strategies to slow the rate of mu-agonist uptake by the brain may produce a beneficial cascade of effects limiting subjective feelings of euphoria and, ultimately, reducing addictive qualities (U.S. Food and Drug Administration, 2015). To date, pharmaceutical companies have concentrated on development of extended-release, abusedeterrent formulations (ADFs) that work to slow the intestinal absorption of traditional opioids, including oxycodone, hydrocodone, and morphine, into the bloodstream. However, in many instances, tampering can readily overcome ADFs. As a result, the liberated opioid enters the brain at a high rate and provides the reward sought by abusers.

Because abuse liability, but not analgesia, is dependent, at least in part, on CNS pharmacokinetics (PK), we hypothesized that separating these two effects could provide a superior solution to the problem. Our objective was to develop a nextgeneration opioid molecule with an inherently slow rate of influx across the $\mathrm{BBB}$ into the CNS that retains the pharmacodynamic activity of traditional mu-opioid agonists. This approach could yield an analgesic with low abuse potential independent of formulation and route of administration. Our efforts resulted in the discovery of $(5 \alpha, 6 \alpha)-4,5$-epoxy-6-(3,6,9,12,15,18hexaoxanonadec-1-yloxy)-3-methoxy-17-methylmorphinan14-ol (NKTR-181), a novel, long-acting, and selective mu-opioid agonist with inherently low abuse potential currently in phase 3 development for the treatment of chronic pain. NKTR-181 not only demonstrated significant analgesic efficacy in patients with chronic low-back pain (manuscript in preparation), but this occurred concomitantly with reduced abuse potential in humans compared with oxycodone (Webster et al., 2017). Taken together, these clinical data suggest that NKTR-181 represents a potential paradigm shift in opioid therapy for chronic pain, providing opioid-induced analgesia with low abuse potential.

Here, we report for the first time the chemical structure of NKTR-181 and compare the effects of NKTR-181 with those of traditional mu-opioid agonists, with respect to rate of brain uptake, receptor binding and function, PK, analgesic action, CNS adverse effects, and drug liking/reinforcing effects. Our preclinical findings demonstrate that NKTR-181 is a novel, selective mu-opioid agonist with analgesic efficacy and reduced abuse liability compared with traditional opioid-agonist pharmacotherapies.

\section{Materials and Methods}

Test Articles. Studies were performed using NKTR-181 hydrochloride salt (Nektar proprietary compound; Nektar Therapeutics, San Francisco, CA), oxycodone hydrochloride (catalog number 01378; Sigma-Aldrich, St. Louis, MO), hydrocodone bitartrate salt (catalog number H4516; Sigma-Aldrich), and morphine sulfate pentahydrate (catalog number M8777; Sigma-Aldrich). Formulations for dosing in animal studies were prepared in saline at appropriate dosing concentrations.

In Situ Brain Perfusion. Male Sprague-Dawley rats (Hilltop Laboratory Animals, Scottsdale, PA) weighing 250-300 g were maintained on a 12-hour light/dark cycle with ad libitum food and water, and housed two per cage. All testing was performed in accordance with the policies and recommendations of the Institutional Animal Care and Use Committee (IACUC) of the testing facility (Absorption Systems, LP, Exton, PA). On the day of study, each rat was anesthetized intraperitoneally (i.p.) with a ketamine $\mathrm{HCl} / x y l a z i n e$ $\mathrm{HCl}$ solution prior to implantation of a cannula into the left carotid artery. Perfusion was performed using a single time-point method, in which perfusate-containing control compounds $(5.0 \mu \mathrm{M}$ antipyrine and $50 \mu \mathrm{M}$ atenolol) and test compound $(10$ or $100 \mu \mathrm{M})$ were infused into the cannula for 30 seconds by infusion pump. After 30 seconds, the perfusion was stopped, and the cerebral tissue was immediately removed from the skull, cut sagittally in half, placed into a chilled tube, frozen on dry ice, and stored at $-60^{\circ} \mathrm{C}$ to $-80^{\circ} \mathrm{C}$ until analysis. Each left hemisphere was thawed and weighed for analysis. Methanol (20\%) was added to each left hemisphere at $4.0 \mathrm{ml} / \mathrm{g}$ tissue, and the mixture was homogenized by sonication (VirSonic Ultrasonic Cell Disruptor 100; The VirTis Company, Gardiner, NY). Liquid chromatography-mass spectrometry/mass spectrometry (LC-MS/MS) analytical methods were used to quantify analytes.

Caco-2 Permeability. Caco-2 monolayers were grown to confluence on collagen-coated, microporous, polycarbonate membranes in 12-well Costar Transwell plates (Corning, Inc., Corning, NY). The permeability assay buffer for the donor chambers was Hanks' balanced salt solution containing $10 \mathrm{mM}$ HEPES and $15 \mathrm{mM}$ glucose at a $\mathrm{pH}$ of 7.4. The buffer in the receiver chambers also contained $1 \%$ bovine serum albumin. The dosing solution concentration of the test compounds was $10 \mu \mathrm{M}$ in the assay buffer. In some studies, the assay buffer and dosing solution contained $100 \mu \mathrm{M}$ verapamil. Cell monolayers were first preincubated for 30 minutes with assay buffer to presaturate $\mathrm{P}$-glycoprotein (P-gp) sites with verapamil. After 30 minutes, the buffer was removed, and the cell monolayers were dosed on the apical (A to B) or basolateral side (B to A) and incubated at $37^{\circ} \mathrm{C}$ with $5 \%$ $\mathrm{CO}_{2}$ in a humidified incubator. After 2 hours, aliquots were taken from the receiver and donor chambers. Each determination was performed in duplicate. To ensure that no damage was inflicted to the cell monolayers during the flux period, we also measured the Lucifer Yellow flux for each monolayer. All samples were assayed by LC-MS/MS using electrospray ionization.

The apparent permeability $\left(\mathrm{P}_{\mathrm{app}}\right)$ and percentage recovery were calculated as follows:

$$
\begin{gathered}
\mathrm{P}_{\mathrm{app}}=\left(d \mathrm{C}_{\mathrm{r}} / d \mathrm{t}\right) \times \mathrm{V}_{\mathrm{r}} /\left(\mathrm{A} \times \mathrm{C}_{\mathrm{A}}\right) \\
\text { percentage recovery }= \\
100 \times\left[\left(\mathrm{V}_{\mathrm{r}} \times \mathrm{C}_{\mathrm{r}}^{\text {final }}\right)\right. \\
\left.+\left(\mathrm{V}_{\mathrm{d}} \times \mathrm{C}_{\mathrm{d}}^{\text {final }}\right)\right] /\left(\mathrm{V}_{\mathrm{d}} \times \mathrm{C}_{\mathrm{N}}\right)
\end{gathered}
$$

where $d \mathrm{C}_{\mathrm{r}} / d \mathrm{t}$ is the slope of the cumulative concentration in the receiver compartment versus time in $\mu \mathrm{M} \mathrm{s}^{-1}, \mathrm{~V}_{\mathrm{r}}$ is the volume of the receiver compartment in $\mathrm{cm}^{3} ; \mathrm{V}_{\mathrm{d}}$ is the volume of the donor compartment in $\mathrm{cm}^{3}$; $\mathrm{A}$ is the area of the cell monolayer $\left(1.13 \mathrm{~cm}^{2}\right.$ for a 12 -well Transwell), $\mathrm{C}_{\mathrm{N}}$ is the nominal dosing concentration of the dosing solution in $\mu \mathrm{M}, \mathrm{C}_{\mathrm{A}}$ is the average of the nominal dosing concentration and the measured 120-minute donor concentration in $\mu \mathrm{M}, \mathrm{C}_{\mathrm{r}}{ }^{\text {final }}$ is the receiver concentration in $\mu M$ at the end of the incubation period, and $\mathrm{C}_{\mathrm{d}}$ final is the concentration of the donor in $\mu \mathrm{M}$ at the end of the incubation period.

The recovery typically was between $75 \%$ and $88 \%$. This study was conducted at Absorption Systems.

Rodent PK. Test articles were dosed either as a single intravenous (tail vein) bolus injection or via oral gavage to overnight-fasted rats. Male Sprague-Dawley rats (Charles River Laboratories, Hollister, CA) weighing between 240 and $280 \mathrm{~g}$ were maintained on a 12-hour light/dark cycle with ad libitum food and water. All testing was performed in accordance with the policies and recommendations of the IACUC of the testing facility (SRI International, Menlo Park, CA). For each time point, a minimum of three animals received either NKTR-181 or oxycodone at the indicated dose levels. At predetermined time points, blood was collected in $\mathrm{K}_{2}$ EDTA-coated microtainer tubes. For rat brain PK, animals were exsanguinated and then 
perfused via the left ventricle with $60 \mathrm{ml}$ of ice-cold saline to remove blood from the organ. Plasma was separated from blood after centrifugation $(10,000 \mathrm{~g}$ for 5 minutes $)$ and kept frozen at $-70^{\circ} \mathrm{C}$ until analysis. Cerebral tissue was removed, weighed, frozen on dry ice, and stored at $-70^{\circ} \mathrm{C}$ until analysis. Proteins from tissue homogenates and plasma samples $(100 \mu \mathrm{l}$ each) were removed by precipitation after adding $300 \mu \mathrm{l}$ of cold acetonitrile. Samples were then centrifuged and analyzed using a qualified LC-MS/MS method in the multiple reaction monitoring (MRM) mode. Chromatographic separation was performed using an optimized isocratic composition of $0.1 \%$ formic acid in $10 \mathrm{mM}$ ammonium acetate $\left(\mathrm{NH}_{4} \mathrm{Ac}\right)$ as mobile phase $\mathrm{A}$ and $0.2 \%$ formic acid in 10:90 water:acetonitrile as mobile phase B.

Noncompartmental analysis was conducted using PhoenixWinNonlin (version 6.4; Pharsight, Mountain View, CA) to obtain PK parameters. Nominal doses and sampling times were used. Maximum plasma concentration $\left(\mathrm{C}_{\max }\right)$ and time of observed maximum plasma concentration $\left(\mathrm{T}_{\max }\right)$ were derived from the input data set. The area under the plasma concentration-time curves (AUC) were calculated using linear-log trapezoidal interpolation and sparse sampling mode and uniform weighing. Terminal half-life was used for extrapolation to infinity $\left(\mathrm{AUC}_{\mathrm{inf}}\right)$. Clearance, volume of distribution at steady state $\left(\mathrm{V}_{\mathrm{ss}}\right)$, and terminal half-life $\left(\mathrm{t}_{1 / 2}\right)$ were determined for NKTR-181 and oxycodone. Percentage absolute bioavailability was estimated as follows: dose-normalized $\mathrm{AUC}_{\text {inf }}$ (p.o.)/AUC $\mathrm{AUf}_{\text {inf }}$ (i.v.) $\times 100$.

The rate of in vivo uptake $\left(\mathrm{K}_{\mathrm{in}}\right)$ was estimated following an intravenous bolus injection at 10 minutes postdose according to eq. 3 :

$$
\mathrm{K}_{\mathrm{in}}=\frac{\mathrm{A}_{\text {brain }}}{\mathrm{AUC}_{0-10, \text { plasma }}}
$$

where $A_{\text {brain }}$ is the amount (ng) in the brain at 10 minutes, and $\mathrm{AUC}_{0-10 \text {, plasma }}(\mathrm{min} * \mathrm{ng} / \mathrm{ml})$ is the area under the plasma curve from $\mathrm{t}=0$ to 10 minutes postdose.

In Vitro Opioid Receptor Binding. Competitive displacement studies were conducted using commercially available membranes prepared from Chinese hamster ovary $(\mathrm{CHO})$ cells heterologously expressing recombinant human mu-, delta-, or kappa-opioid receptors (PerkinElmer, Richmond, CA). $\left[{ }^{3} \mathrm{H}\right]$ Naloxone, $\left[{ }^{3} \mathrm{H}\right]$ DPDPE, and $\left[{ }^{3} \mathrm{H}\right]$ diprenorphine were used as the radioligands for $\mathrm{mu}$, delta, and kappa receptors, respectively. Membranes containing the receptor of interest were incubated with increasing concentrations of test compound in the presence of a single concentration of radioligand. The fixed concentration of the radioligand used was at the reported $K_{d}$ for the receptor. Serial dilutions of the test compound were prepared, and each concentration was tested in triplicate. Nonspecific binding was measured in the presence of excess naloxone; this value was subtracted from the total binding to yield the specific binding at each test concentration. Calculations for saturation binding, 50\% inhibition $\left(\mathrm{IC}_{50}\right)$, and $\mathrm{K}_{\mathrm{i}}$ were determined using published calculations (Cheng and Prusoff, 1973; Leslie, 1987; Motulsky and Christopoulos, 2004; McKinney and Raddatz, 2006). Data were analyzed using GraphPad Prism (GraphPad Software Inc., La Jolla, CA).

In Vitro Opioid Receptor Function. In vitro intrinsic efficacy was evaluated by measuring the reduction of cAMP levels (inhibition of cAMP formation) in forskolin-stimulated CHO cells that heterologously express the cloned human mu-, kappa-, or delta-opioid receptors (Nektar Therapeutics). The cells were pretreated with buffer containing the phosphodiesterase inhibitor 3-isobutyl-1-methylxanthine and then with forskolin and varying concentrations of morphine, oxycodone, hydrocodone, or NKTR-181, with each concentration tested in triplicate. Inhibition of forskolin-stimulated cAMP formation was measured using a cAMP HiRange homogeneous time-resolved fluorescence assay that is based on the principle of a competitive immunoassay (catalog number 62 AM6PEC; Cisbio, Bedford, MA). Results were calculated from the fluorescence ratio $(665 / 620 \mathrm{~nm})$. The $\mathrm{EC}_{50}$ was calculated using XLfit4 software (IDBS, Boston, MA).

Acetic-Acid Writhing Test. The acetic-acid writhing test of visceral pain in the mouse was used to assess acute antinociceptive effects. Male Swiss Webster (CD-1) mice (Charles River Laboratories, Hollister, CA) weighing $\sim 20 \mathrm{~g}$ at the start of the study were housed five per cage and maintained on a 12-hour light/dark cycle with ad libitum food and water. All testing was performed during the light cycle and in accordance with the policies and recommendations of the IACUC of the testing facility (SRI International). Mice received NKTR-181 or oxycodone orally at doses of 0 (saline), $1,3,10,30$, or $100 \mathrm{mg} / \mathrm{kg}$ $(n=10 /$ dose level). One hour after administration of test articles, mice were given an i.p. injection of $0.5 \%$ acetic acid in water $(10 \mathrm{ml} / \mathrm{kg})$ to induce writhing. Writhing included the following behaviors: contractions of the abdomen, twisting and turning of the trunk, arching of the back, and extension of the hindlimbs. Naïve animals were randomly assigned to groups on the day of dose, and each observer was blinded to the treatment groups. After the i.p. injection, the animals were placed in clear plastic beakers and their behavior observed. Single writhing episodes were counted during a 20 -minute period immediately after the i.p. injection. Immediately after the end of the behavioral study, animals were anesthetized with isoflurane and blood samples were taken. After blood sampling, animals were euthanized by cervical dislocation. Statistical significance for dose response was evaluated using one-way analysis of variance (ANOVA), Dunnett's post-test with respect to saline using GraphPad Prism (GraphPad Software Inc.). The $\mathrm{ED}_{50}$ was calculated using WinNonlin 5.2.1, Model 104 (Pharsight, Mountain).

Hot-Plate Latency. Analgesic efficacy to thermal nociception was evaluated using the hot-plate latency test. Male Swiss Webster (CD-1) mice (Charles River Laboratories, Raleigh, NC) weighing 16-20 g at the start of the study were housed 10 per cage and maintained on a 12-hour light/dark cycle with ad libitum food and water. For the rat time-course study, male CD IGS rats (Charles River Laboratories, Raleigh, NC) weighing 101-125 g were received, housed four per cage, and maintained on a 12-hour light/dark cycle with ad libitum food and water for 1 week before the start of the study. All testing was performed during the light cycle and in accordance with the IACUC of the testing facility (Howard Associates, LLC, Durham, NC). Compound (NKTR-181 or oxycodone) was administered orally, and 30 minutes later we measured hot-plate latency (time to response by licking hind paw or jumping) after placement on a $55^{\circ} \mathrm{C}$ hot plate. A saline control was included and evaluated at 1 hour postdose. The time to lick or jump was recorded; however, if no lick or jump occurred within 30 seconds, the animal was removed and 30 seconds was recorded as response latency. Testers were blinded to the treatment groups. Immediately after the last time point, the mouse was euthanized by $\mathrm{CO}_{2}$ inhalation, and samples were collected for PK analysis (data not shown). Statistical significance for dose response was evaluated using one-way ANOVA, Dunnett's post-test with respect to saline. Two-way repeated-measures ANOVA was used to evaluate time-course response. Statistical significance was indicated where $P<0.05$ (two-tailed test). The $\mathrm{ED}_{50}$ was calculated with the lower bound at the saline mean and the upper bound at the cutoff point, 30 seconds. Data were analyzed using GraphPad Prism (GraphPad Software Inc.).

Modified Irwin Test. The modified Irwin test consisted of observations of CNS-mediated behavior (Roux et al., 2005). Naïve male Swiss Webster (CD-1) mice (Charles River Laboratories, Raleigh, NC) weighing 16-18 $\mathrm{g}$ at the start of the study were housed 10 per cage and maintained on a 12-hour light/dark cycle with ad libitum food and water. All testing was performed during the light cycle and in accordance with the policies and recommendations of the IACUC of the testing facility (Howard Associates, LLC). NKTR-181, oxycodone, or saline was administered orally, and each mouse was placed immediately in the observation chamber. At each time point, undisturbed observations were made for gross signs of hyper- or hypoactivity, Straub tail (rigidity in the tail that is commonly observed in mice administered with opioid agonists), hindlimb splay, tremor, and seizure. Then, each mouse was handled for evaluation of muscle tone (rigid or not), pinna reflex (presence or absence), righting reflex (intact or lost), and placing (whether or not the forepaws were 
extended when the mouse was placed near the surface). On the next day, each mouse was inspected for any gross physiologic abnormality, and then immediately euthanized by $\mathrm{CO}_{2}$ inhalation.

Rotarod. Locomotor coordination was evaluated using the rotarod test. Male Sprague-Dawley rats (Charles River Laboratories, Hollister, CA) weighing between 240 and $280 \mathrm{~g}$ were housed two to three per cage and maintained on a 12-hour light/dark cycle with ad libitum food and water. All testing was performed during the light cycle and in accordance with the policies and recommendations of the IACUC of the testing facility (SRI International). Naïve rats were trained to run on the treadmill for 2 consecutive days before the day of study, when trained animals were placed on the rotarod and baseline scores recorded. After baseline assessment, animals were randomized into groups and received oral doses of saline, oxycodone (10-100 mg/kg), or NKTR-181 (10-300 mg/kg). Then, each rat's performance on the rotarod was evaluated 30 and 60 minutes later. The tester was blinded to the treatment groups. The rod rotation was set at a constant speed of $4 \mathrm{~g}$ for 15 seconds, then set to accelerate from 4 to $40 \mathrm{~g}$ over a 5 -minute period. The time (in seconds) at which each animal stopped running and fell off the rotarod was recorded as the time spent on the rotarod. Animals that ran for 300 seconds were taken off the rotarod and 300 seconds was recorded. Statistical significance was evaluated using two-way repeated-measures ANOVA with Bonferroni post-test with respect to saline. Statistical significance was indicated where $P<0.05$ (two-tailed test). Data were analyzed using GraphPad Prism (GraphPad Software Inc.).

Abuse Potential: Self-Administration and Progressive Ratio. Male Sprague-Dawley rats (Charles River Laboratories, Portage, MI) were received at approximately 7.5 weeks of age, and studies were conducted at MPI Research, Inc. (Mattawan, MI). All animals were surgically implanted with chronic indwelling jugular catheters per Charles River Laboratories standard operating procedures, using specialized catheters provided by MPI Research, Inc. Animals were housed individually and maintained on a 12-hour light/dark cycle with ad libitum food and water. One week after receipt, access to food was limited to maintain animals at $85 \%-95 \%$ of the free-feeding weight during lever-pressing training, with supplemental feedings earned during training operant sessions, as assessed once during the study. During applicable operant sessions, animals received Dustless Precision Pellets, $45 \mathrm{mg}$, Rodent Grain-Based Diet (Bio-Serv, Flemington, $\mathrm{NJ})$. All training and testing were conducted during the light cycle.

Training and generalization were conducted as described in the literature (Gauvin et al., 2015). In brief, once animals were trained to respond consistently under the fixed-ratio four with food (four consecutive lever presses per food reward), then animals were transitioned to respond to cocaine infusion $(0.56 \mathrm{mg} / \mathrm{kg}$ per infusion). Cocaine is a standard substance for initial reinforcement training in this model, and the particular history used to establish reinforcement behavior does not affect the later behavior shown in the test compounds (e.g., oxycodone and NKTR-181). Infusion training sessions were terminated after a maximum of approximately 1 hour in duration and a maximum of 10 rewards. After training, animals that consistently provided 10 responses for each cocaine infusion (FR10), with less than $20 \%$ day-to-day variation over 3 consecutive days, were used for the study.

Self-administration was evaluated during the testing and substitution sessions; the parameter reported for abuse liability indication is total number of infusions during the session. Exposures to saline or cocaine were considered test sessions, and exposures to the test compounds were considered substitution sessions. Test and substitution sessions were identical to training sessions except for the drug or drug dose that was self-administered, and no restriction was placed on the number of rewards attainable. Operant testing sessions were interspersed between cocaine maintenance training sessions. In the substitution sessions, NKTR-181 was administered at $0.032,0.1,0.32,1.0$, and $3.2 \mathrm{mg} / \mathrm{kg}$ per infusion. Oxycodone was administered at $0.0032,0.01,0.032$, and $0.1 \mathrm{mg} / \mathrm{kg}$ per infusion. All treatments were administered at a dose volume less than $1 \mathrm{ml}$ per

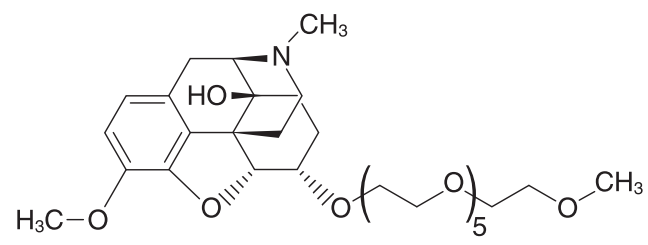

Fig. 1. Chemical structure of NKTR-181.

infusion. Six animals were tested per dose level. Animals tested were exposed to each treatment condition once per day for three consecutive sessions.

The progressive-ratio break points were determined by the highest number of responses emitted by the animal to receive a single drug delivery. In the progressive-ratio schedule, the total number of leverpress responses required for each subsequent drug delivery was incremented using a logarithmic (base e) scale using the following equation:

$$
\text { response requirement }=5 * \mathrm{e}^{(\text {response increment*0.2) }}-5
$$

After the maintenance training session, a second substitution test was conducted under the progressive-ratio schedule of drug delivery.

Data Availability. All relevant data are available from the authors.

\section{Results}

NKTR-181 Has a Reduced Rate of Brain Entry Relative to Traditional Opioid Agonists. We previously reported that derivatives of morphine-like (morphinan) scaffolds containing short-chain polyethylene glycol functional groups have altered oral bioavailability and reduced penetration across the BBB (Corsetti and Tack, 2015; Bui et al., $2016 a, b)$. We extended this work to screen a library of polymercontaining morphinan opioid agonists for their activity, bioavailability, and kinetics of BBB penetration. We selected NKTR-181 from these compounds as the first exemplar of this new class of opioid agonists with reduced influx into the CNS in vivo (Fig. 1).

Rates of brain uptake $\left(\mathrm{K}_{\mathrm{in}}\right)$ for NKTR-181 and traditional opioids were determined by measuring relative concentrations in the brain after a 30 -second, single perfusion at 10 or $100 \mu \mathrm{M}$ in the rat (in situ brain perfusion; Table 1). Oxycodone, a readily brain-penetrant opioid, displayed consistent uptake values at both concentrations. Hydrocodone had reduced brain uptake compared with oxycodone, but was still measurable in the brain at appreciable amounts $(507 \pm$ $192 \mathrm{pmol} / \mathrm{g}$ ). NKTR-181 had a reduced rate of brain entry compared with oxycodone and hydrocodone, measuring

\section{TABLE 1}

Rate of brain entry $\left(\mathrm{K}_{\mathrm{in}}\right)$ following intravenous delivery of test article in anesthetized rats ( $n=4$ /group) in an in situ brain perfusion model Data are presented as means \pm S.E.M.

\begin{tabular}{lcc}
\hline \multirow{2}{*}{ Test Article } & \multicolumn{2}{c}{$\mathrm{K}_{\text {in, perfusion }}(\mathrm{ml} / \mathrm{g} / \mathrm{min})$} \\
\cline { 2 - 3 } & $10 \mu \mathrm{M}$ & $100 \mu \mathrm{M}$ \\
\hline & $\mathrm{ml} / \mathrm{g} / \mathrm{min}$ & $\mathrm{ml} / \mathrm{g} / \mathrm{min}$ \\
Hydrocodone & $0.091 \pm 0.034$ & $\mathrm{ND}$ \\
Oxycodone & $0.497 \pm 0.121$ & $0.560 \pm 0.056$ \\
NKTR-181 & $0.007 \pm 0.005$ & $0.008 \pm 0.005$ \\
\hline
\end{tabular}

$\mathrm{ND}$, not determined. 
TABLE 2

Apparent permeability in Caco-2 cells with compounds tested at $10 \mu \mathrm{M}$ in assay buffer, with or without verapamil $100 \mu \mathrm{M}$

Apparent permeability $\left(\mathrm{P}_{\text {app }}\right)$ and efflux ratio are reported.

\begin{tabular}{lccc}
\hline \multicolumn{1}{c}{ Test Article } & $\mathrm{P}_{\text {app }}$ A-to-B $(10-6 \mathrm{~cm} / \mathrm{s})$ & $\mathrm{P}_{\text {app }}$ B-to-A $(10-6 \mathrm{~cm} / \mathrm{s})$ & Efflux Ratio \\
\hline Oxycodone & 32.8 & 31.1 & 1 \\
Oxycodone + verapamil $100 \mu \mathrm{M}$ & 33.1 & 26.6 & 0.8 \\
NKTR-181 & 0.87 & 8.55 & 9.8 \\
NKTR-181 + verapamil $100 \mu \mathrm{M}$ & 3.07 & 2.84 & 0.8 \\
\hline
\end{tabular}

71-fold less than oxycodone and 13-fold less than hydrocodone (Table 1).

The observed reduction in rate of brain entry for NKTR-181 compared with oxycodone in rats (Table 1) correlated with both reduced permeability and increased P-gp-mediated efflux, which we observed in experiments showing reduced flux across a Caco-2 cell monolayer (Table 2). Although $100 \mu \mathrm{M}$ verapamil completely neutralized P-gp-mediated efflux across Caco-2 monolayers, it is noteworthy that the intrinsic permeability of NKTR-181 is approximately one order of magnitude less than that of oxycodone. Therefore, the rate of entry of NKTR-181 into the brain is expected to be considerably slower than that of oxycodone, even in the presence of physiologically attainable P-gp inhibitor plasma concentrations.

This reduced rate of brain uptake of NKTR-181 was replicated using rat $\mathrm{PK}$, measuring brain concentrations after intravenous doses. $\mathrm{K}_{\mathrm{in}}$, determined by measuring brain concentrations over time, was more than 17-fold less for NKTR-181 than for oxycodone $(0.007$ vs. $0.124 \mathrm{ml} / \mathrm{min}$, respectively; Table 3). In addition, rat PK experiments showed that oral bioavailability was approximately 9 -fold greater for NKTR-181 compared with oxycodone ( $34 \%$ vs. $4 \%$, respectively; Table 3).

NKTR-181 Has Full Functional Activity and Selectivity at the MOR. NKTR-181 displayed higher binding affinity at the MOR than at the kappa- and delta-opioid receptors. At the MOR, the affinity of NKTR-181 was less than the affinities of traditional opioids (morphine and oxycodone), between 15- and 28-fold less potent. The traditional MOR agonists exhibit full displacement of $\left[{ }^{3} \mathrm{H}\right]$ naloxone, and we observed the same result for NKTR-181 (Table 4).

Activation of $\mathrm{G}_{\mathrm{i}}$-coupled receptor, including opioid receptors, leads to inhibition of adenylate cyclase and decreased accumulation of cAMP (Seamon et al., 1981; Milligan and Kostenis, 2006). In forskolin-stimulated CHO cells heterologously expressing the human MOR, NKTR-181 produced a concentration-dependent inhibition of cAMP accumulation with an $\mathrm{EC}_{50}$ value of $12.5 \pm 3.4 \mu \mathrm{M}$ (mean \pm S.D.), as well as full agonist activity, with maximal efficacy at saturating concentrations comparable to that of the other traditional mu agonists (Table 5). There was no measurable inhibition of cAMP accumulation with NKTR-181 when tested at the kappa- and delta-opioid receptors at concentrations up to $500 \mu \mathrm{M}$. These data demonstrate that NKTR-181 acts as a full agonist with high selectivity for MOR, and supports the hypothesis that NKTR-181 mediates its opioid-like effects in vivo by activation of endogenous MORs.

NKTR-181 Delivers Full Analgesic Activity with Durable Effect. To evaluate the centrally mediated analgesic activity via the MOR, we analyzed NKTR-181 in two typical models (writhing and hot-plate tests). As evaluated using the mouse acetic-acid writhing test, oral administration of NKTR-181 achieved complete inhibition of writhing response (as did oral administration of oxycodone), with an estimated $\mathrm{ED}_{50}$ of $8.9 \mathrm{mg} / \mathrm{kg}$ at 1 hour postinjection (Fig. 2). In the mouse hot-plate test, full analgesic efficacy was similar to that of oxycodone; maximal latency was achieved at the highest dose tested 30 minutes after oral administration (Fig. 3).

For the time-course study, we evaluated NKTR-181 and oxycodone in mouse and rat hot-plate tests. For the mouse time-course study, data from the 30-minute time point were used to estimate $\mathrm{ED}_{50}$ values $(68 \mathrm{mg} / \mathrm{kg}$ for NKTR-181 and $2.3 \mathrm{mg} / \mathrm{kg}$ for oxycodone, Fig. 3), and hot-plate latency of that dose was measured at additional time points $(0.5,1,2,4$, and 6 hours postdose). The response latency of NKTR-181 at 0.5 -hour postdose persisted during the 6 -hour test time (Fig. 4A). In addition, the effect of NKTR-181 and oxycodone was significantly different [two-way ANOVA $\mathrm{F}(1,9)=31.04$, $P=0.0003]$. This durable analgesic effect was reproduced in the rat hot-plate test. NKTR-181 $(170 \mathrm{mg} / \mathrm{kg})$ had a significant analgesic effect up to 4 hours after a single dose (statistical significance to saline at 4 hours: $P=0.0028$, whereas the analgesic action of oxycodone $(17 \mathrm{mg} / \mathrm{kg}$ ) lasted for a maximum of 1 hour (statistical significance to saline at 1 hour: $P=0.0002$; Fig. $4 \mathrm{~B}$ ).

TABLE 3

Plasma pharmacokinetics (data presented as means \pm S.D.) following a bolus i.v. ( $1 \mathrm{mg} / \mathrm{kg}$ ) and p.o. (5 mg/kg) administration to Sprague Dawley rats ( $n=3$ /group)

Intravenous parameters include total clearance $(\mathrm{CL})$, volume of distribution $\left(\mathrm{V}_{\mathrm{ss}}\right)$, half-life $\left(\mathrm{t}_{1 / 2}\right)$, and brain uptake over time $\left(\mathrm{K}_{\mathrm{in}}\right)$. Oral parameters include maximal plasma concentration $\left(\mathrm{C}_{\max }\right)$, area under the curve (AUC), time to maximal plasma concentration $\left(\mathrm{T}_{\max }\right)$, and percentage oral availability $(\mathrm{F})$.

\begin{tabular}{|c|c|c|c|c|c|c|c|c|}
\hline \multirow{2}{*}{ Test article } & \multicolumn{4}{|c|}{ i.v. } & \multicolumn{4}{|c|}{ p.o. } \\
\hline & CL & $\mathrm{V}_{\mathrm{ss}}$ & $t_{1 / 2}$ & $\mathrm{~K}_{\text {in }}$ & $\mathrm{C}_{\max }$ & $\mathrm{AUC}_{\text {inf }}$ & $\mathrm{T}_{\max }$ & $\mathrm{F}$ \\
\hline & $\mathrm{ml} / \mathrm{min} / \mathrm{kg}$ & $\mathrm{l} / \mathrm{kg}$ & $h$ & $\mathrm{ml} / \mathrm{min}$ & $\mathrm{ng} / \mathrm{ml}$ & $\min * \mathrm{ng} / \mathrm{ml}$ & $h$ & $\%$ \\
\hline Oxycodone & $49.2 \pm 7.1$ & $1.72 \pm 0.25$ & $0.76 \pm 0.25$ & 0.124 & $53.9 \pm 45.1$ & $75.6 \pm 64.0$ & $0.3 \pm 0.1$ & $4.40 \pm 3.7$ \\
\hline NKTR-181 & $59.3 \pm 8.1$ & $4.19 \pm 0.70$ & $4.53 \pm 1.10$ & 0.007 & $100.7 \pm 18.4$ & $483.3 \pm 97.9$ & $1.8 \pm 1.3$ & $34.0 \pm 6.9$ \\
\hline
\end{tabular}


TABLE 4

Receptor binding affinity of traditional mu-opioid agonists (morphine and oxycodone) and NKTR-181 at mu-, delta-, and kappa-opioid receptors

\begin{tabular}{lccc}
\hline & \multicolumn{3}{c}{$\mathrm{K}_{\mathrm{i}}($ mean \pm S.D. $)$} \\
\cline { 2 - 4 } & $\mathrm{Mu}$ & \multicolumn{1}{c}{ Delta } & Kappa \\
\hline Morphine & $n M$ & $n M$ & $n M$ \\
Oxycodone & $16.0 \pm 1.3$ & $4,300 \pm 500$ & $118 \pm 25$ \\
NKTR-181 & $237 \pm 31$ & $7,680 \pm 1,200$ & $43,000 \pm 1,800$ \\
\hline
\end{tabular}

NKTR-181 Demonstrates an Acceptable CNS-Mediated Adverse Event Profile at Efficacious Analgesic Doses. Although mu agonists are useful in pain management, this class of drug is associated with severe adverse events, including sedation. Here, we assessed CNS-mediated effects of NKTR-181 on mouse behavior using the modified Irwin test. Behavioral abnormalities were less prominent for NKTR-181 in both the number of incidents within a specific behavior and the variety of observed CNS-related behavioral responses compared with oxycodone. Incidence of Straub tail required a $300-\mathrm{mg} / \mathrm{kg}$ dose of NKTR-181-300-fold higher (158-fold higher molar equivalent dose) than oxycodone (Fig. 5).

In the rat rotarod test, oxycodone showed impairment of motor coordination at 0.5 hour postdose even at the lowest dose tested, $10 \mathrm{mg} / \mathrm{kg}(P<0.05)$, and the maximal impairment was reached at $30 \mathrm{mg} / \mathrm{kg}$. However, NKTR-181 treatment resulted in moderate locomotor coordination defects compared with saline at 0.5 hour postdose $(P<0.05)$ and at 1 hour postdose $(P<0.001)$ only at the highest tested dose, $300 \mathrm{mg} / \mathrm{kg}$ (Fig. 6).

NKTR-181 Demonstrates Less Abuse Potential Compared with Oxycodone. Administration of NKTR-181 showed no evidence of reinforcing behavior in rats in a well established behavioral model of abuse potential. In an assessment of self-administration, NKTR-181 did not serve as a positive reinforcer of initiation or maintenance of lever-press responding for test doses up to 1000 -fold higher than those needed to engender lever-press responding by oxycodone (Fig. 7).

Direct intravenous infusions of NKTR-181 demonstrated an effect similar to that of saline, even at the highest concentrations tested, with a clear and distinct downward-staircase extinction pattern of lever-press responding on subsequent days. Despite high intravenous concentrations of NKTR-181 $(>5000 \mathrm{nmol} / \mathrm{kg}$ ), the drug did not produce reinforcing effects in this assay. In contrast, $9.1 \mathrm{nmol} / \mathrm{kg}$ oxycodone maintained

\section{TABLE 5}

Functional activity and $\mathrm{EC}_{50}$ for inhibition of cAMP formation of morphine, oxycodone, and NKTR-181 at mu-, kappa-, and delta-opioid receptors

\begin{tabular}{lccc}
\hline & \multicolumn{3}{c}{$\mathrm{EC}_{50}($ mean \pm S.D. $)$} \\
\cline { 2 - 4 } & $\mathrm{Mu}$ & Delta & Kappa \\
\hline & $\mu M$ & $\mu M$ & $\mu M$ \\
Morphine & $0.0285 \pm 0.006$ & $\mathrm{ND}$ & $0.624 \pm 0.15$ \\
Oxycodone & $0.48 \pm 0.19$ & $>10,000$ & $>10,000$ \\
NKTR-181 & $12.5 \pm 3.4$ & $>10,000$ & $>10,000$ \\
\hline
\end{tabular}

$\mathrm{ND}$, not determined.
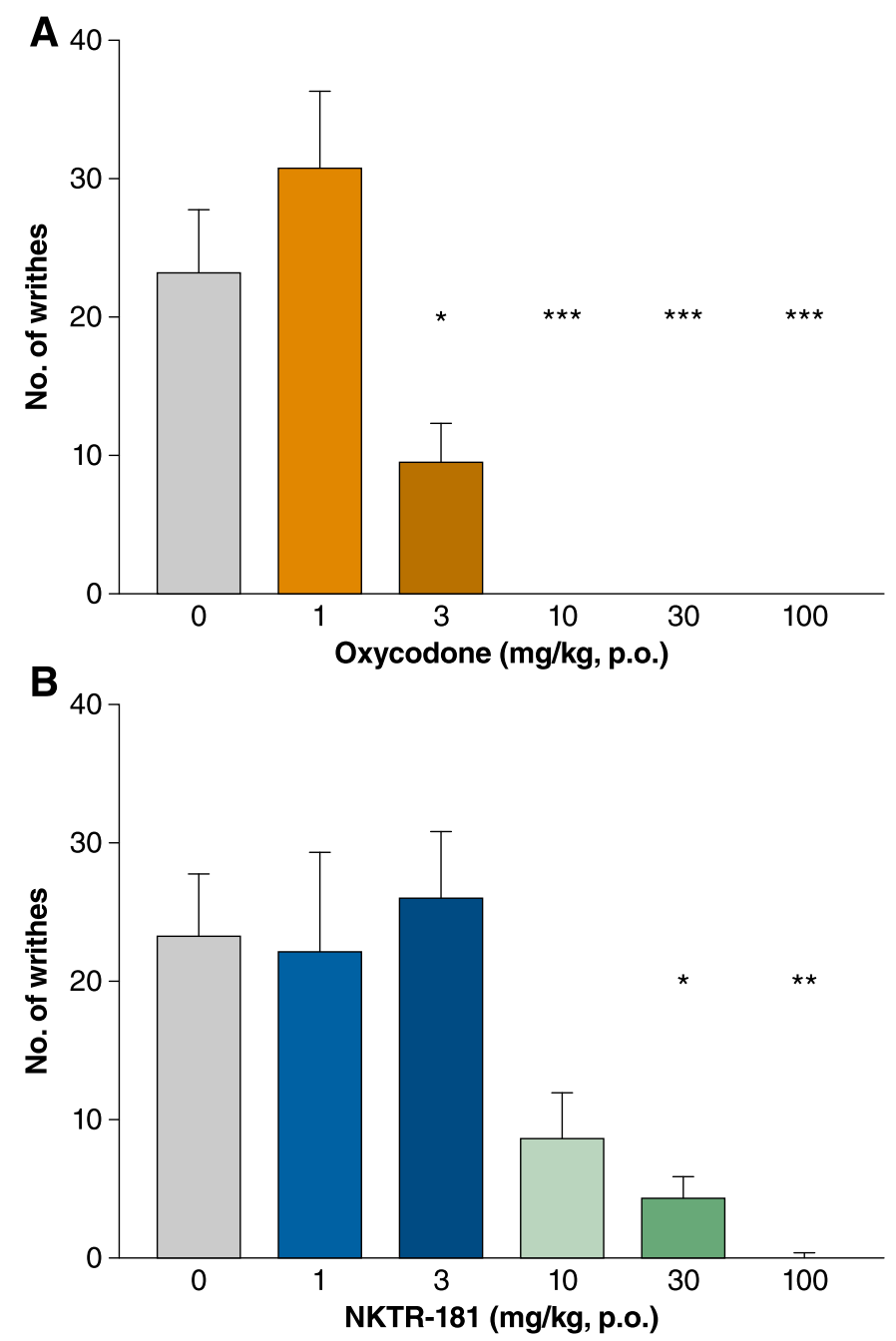

Fig. 2. Mouse acetic-acid writhing dose response for oxycodone (A) and NKTR-181 (B) at 1 hour postdose. Data represent mean \pm S.E.M. values $(n=10)$. Statistical significance was determined using Dunnett's post-test with respect to saline $\left(* P<0.05 ; * * P<0.01\right.$; $\left.{ }^{* * *} P<0.001\right)$. Ratio of molar equivalent doses for NKTR-181 to oxycodone is 1.8 to 1 .

self-administration. The bell-shaped response observed with reduced self-administration at the highest concentration of oxycodone is common to all drugs of abuse. At the highest doses, direct motor effects of the drug begin to affect behavioral patterns of self-administration (Gauvin et al., 2015).

These lower rates of self-administration with NKTR-181 were also reflected in a reduced propensity or motivation to work increasingly harder to receive subsequent infusions of NKTR-181 in a progressive-ratio model (Fig. 8). Progressiveratio "break points" were used to determine the relative work (consecutive lever presses) an animal was willing to exert to receive a single dose of drug. This is a standard method for evaluating and comparing the relative reinforcing efficacy or hedonic valence of drugs, which directly correlates with their abuse liability (Panlilio and Goldberg, 2007). Unlike cocaine and oxycodone, for which rats were willing to perform a heightened number of lever presses to receive additional infusions, NKTR-181 displayed behavior similar to that seen with saline, even at milligram-per-kilogram doses 320 -fold higher than the lower dose of oxycodone. 

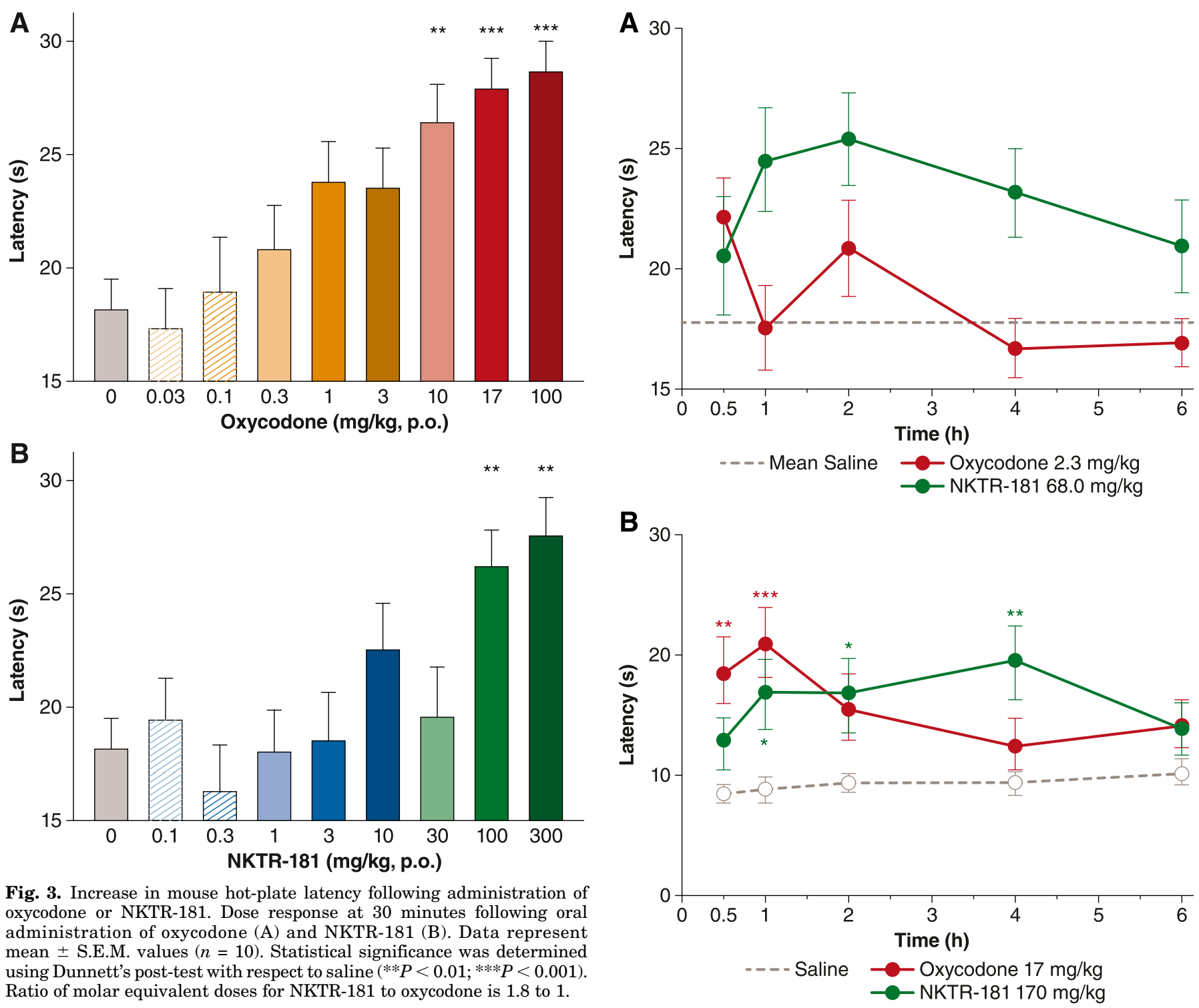

Fig. 3. Increase in mouse hot-plate latency following administration of oxycodone or NKTR-181. Dose response at 30 minutes following oral administration of oxycodone (A) and NKTR-181 (B). Data represent mean \pm S.E.M. values $(n=10)$. Statistical significance was determined using Dunnett's post-test with respect to saline ( ${ }^{* *} P<0.01$; $* * * P<0.001$ ). Ratio of molar equivalent doses for NKTR-181 to oxycodone is 1.8 to 1.

\section{Discussion}

Prescription opioid analgesics are an effective and necessary means of treating severe acute and chronic pain, but their abuse, misuse, and diversion have become an epidemic of national and international proportions (Manchikanti et al., 2012; Rudd et al., 2016). The speed at which traditional opioid agonists, such as oxycodone, enter the brain has a significant impact on abuse potential (Raffa et al., 2012). Current strategies to address abuse liability rely on extended-release formulations to slow the rate of systemic absorption through the gut, ultimately slowing brain absorption and reducing the impact of opioid-associated euphoria. However, once the active opioid agonist enters the circulation, any benefit achieved by the formulation is lost as the released opioid, whether from an extended- or immediate-release formulation, behaves the same: rapidly crossing the BBB and entering the CNS. Thus, extended-release formulations retain the potential to be misused when the opioid contained within them is recovered through tampering and/or introduced rapidly into the

Fig. 4. Time course of latency to respond following single administration of oxycodone or NKTR-181 in the mouse (A) and rat (B) hot-plate test. Measurements were taken at 0.5, 1, 2, 4, and 6 hours postdose. Statistical significance was determined using two-way ANOVA, Dunnett's post-test with respect to saline $\left(* P<0.05 ;{ }^{* *} P<0.01 ; * * * P<0.001\right)$. Ratio of molar equivalent doses for NKTR-181 to oxycodone is 1.8 to 1 ( $n=10$ /group).

circulation by alternative routes of administration, such as insufflation or intravenous injection.

In our approach, we invented a next-generation opioid agonist, which, based on its physicochemical properties, has a significantly reduced rate of flux across the BBB compared with traditional opioid-agonist medicines. The addition of a polyethylene glycol functional group to a small molecule changes not only its oral availability, but also its distribution across the BBB. This feature is demonstrated by the activity of naloxegol (Movantik; Astra Zeneca, Cambridge, UK), which is effectively restricted to peripheral tissues outside of the CNS (Corsetti and Tack, 2015; Bui et al., 2016a,b). In NKTR-181, addition of a polyethylene glycol side chain to a morphine-like (morphinan) pharmacophore confers a slower rate of brain uptake than traditional opioids while retaining activity as a selective mu-opioid agonist. 


\begin{tabular}{|c|c|c|c|c|c|c|c|c|c|c|}
\cline { 2 - 10 } \multicolumn{1}{c|}{} & \multicolumn{5}{c|}{ Oxycodone } & \multicolumn{5}{c|}{ NKTR-181 } \\
\hline $\begin{array}{c}\text { Dose } \\
(\mathbf{m g} / \mathbf{k g})\end{array}$ & $\begin{array}{c}\text { Muscle } \\
\text { Rigid }\end{array}$ & $\begin{array}{c}\text { Straub } \\
\text { Tail }\end{array}$ & $\begin{array}{c}\text { Loss } \\
\text { Pinna }\end{array}$ & $\begin{array}{c}\text { Loss } \\
\text { Right }\end{array}$ & $\begin{array}{c}\text { Loss } \\
\text { Place }\end{array}$ & $\begin{array}{c}\text { Muscle } \\
\text { Rigid }\end{array}$ & $\begin{array}{c}\text { Straub } \\
\text { Tail }\end{array}$ & $\begin{array}{c}\text { Loss } \\
\text { Pinna }\end{array}$ & $\begin{array}{c}\text { Loss } \\
\text { Right }\end{array}$ & $\begin{array}{c}\text { Loss } \\
\text { Place }\end{array}$ \\
\hline $\mathbf{0 . 3}$ & & & & & & & & & & \\
\hline $\mathbf{1}$ & & 1 & & & & & & & & \\
\hline $\mathbf{3}$ & & 2 & & & & & & & & \\
\hline $\mathbf{1 0}$ & 2 & 2 & 1 & & & & & & & \\
\hline $\mathbf{3 0}$ & 2 & 2 & 1 & & & & & & & \\
\hline $\mathbf{1 0 0}$ & 2 & 2 & 2 & & & 1 & & & & \\
\hline $\mathbf{3 0 0}$ & 2 & 2 & 2 & & & 1 & 1 & & & \\
\hline
\end{tabular}

Fig. 5. Modified Irwin test measuring CNS-mediated behavioral responses following oral administration of oxycodone or NKTR-181. Numbers indicate mice displaying each behavior at a respective dose ( $n=2$ /group; green $=$ no mice, yellow $=1$ mouse, red $=2$ mice). Time of maximal behavioral observation was averaged across behaviors. Earliest observations made were 0.5 hour for oxycodone and 2 hours for NKTR-181. Definitions of each category: muscle tone (rigid or not), Straub tail (tail is rigid and erect), loss pinna (absence of ear reflex), loss right (loss of righting reflex), and loss place (loss of forepaw extension when mouse is placed near a surface). Ratio of molar equivalent doses for NKTR-181 to oxycodone is 1.8 to 1 . Molar conversions of doses tested: 1 (2.8 $\mu \mathrm{mol} / \mathrm{kg}$ oxycodone, $1.6 \mu \mathrm{mol} / \mathrm{kg}$ NKTR-181), 3 (8.5 $\mu \mathrm{mol} / \mathrm{kg}$ oxycodone, $4.7 \mu \mathrm{mol} / \mathrm{kg}$ NKTR-181), 10 (28 $\mu \mathrm{mol} / \mathrm{kg}$ oxycodone, $16 \mu \mathrm{mol} / \mathrm{kg} \mathrm{NKTR-181),}$

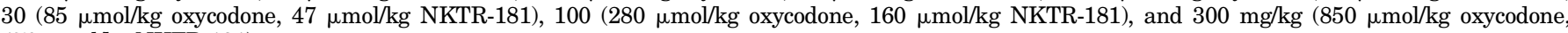
$470 \mu \mathrm{mol} / \mathrm{kg}$ NKTR-181).

NKTR-181 has a 17- to 70-fold lower rate of brain entry in rats as compared with oxycodone, which is the result of a combination of reduced permeability and increased P-gp-mediated efflux at the BBB. Importantly, no chemical or physical tampering method has yet been identified that can alter the NKTR-181 molecule to an active form that has a higher rate of entry into the CNS. In fact, to date, all efforts to chemically manipulate the molecule (Cone et al., 2013) so as to remove the polymer functional group have degraded the pharmacophore, rendering it inactive as a mu-opioid agonist (data not shown). In accordance with U.S. Food and Drug Administration guidelines, these findings were confirmed by a third-party laboratory (Drugscan, Horsham, PA).

NKTR-181 is a full MOR agonist in vitro and achieved maximum analgesic efficacy in mouse models equivalent to treatment with oxycodone. In the mouse acetic-acid writhing model, 1-hour postdose NKTR-181 had an $\mathrm{ED}_{50}$ 1.8-fold higher (molar equivalent) compared with oxycodone, whereas in the hot-plate latency assay at 0.5 -hour postdose, the $\mathrm{ED}_{50}$ was 16-fold higher (molar equivalent) for NKTR-181 compared with oxycodone. The unique physicochemical properties of NKTR-181 also impart an extended PK profile in the circulation compared with oxycodone, effectively eliminating the need for an extended-release formulation for NKTR-181 with twice-daily dosing. When dosed at its 0.5 -hour postdose $\mathrm{ED}_{50}$, NKTR-181 demonstrated a prolonged analgesic effect for up to 6 hours. This result reflects the improved oral bioavailability and extended PK profile of NKTR-181 compared with oxycodone.

Most importantly perhaps, the nonanalgesic CNS effects of NKTR-181 are relatively mild at therapeutic (analgesic) dose levels. CNS-mediated adverse effects on mouse behavior, as measured using the modified Irwin test, were not observed at doses below $100 \mathrm{mg} / \mathrm{kg}$ and were very limited even at the $300-\mathrm{mg} / \mathrm{kg}$ dose. To put this observation into perspective, NKTR-181 had an $\mathrm{ED}_{50}$ of $68 \mathrm{mg} / \mathrm{kg}$ at 0.5 hour in the mouse hotplate latency assay, with substantial analgesic efficacy at 2 hours postdose (the same time point at which the modified Irwin test was conducted). These findings demonstrate that NKTR-181 has an acceptable CNS adverse effect profile at efficacious analgesic doses. In comparison, oxycodone had an $\mathrm{ED}_{50}$ of $2.3 \mathrm{mg} / \mathrm{kg}$ at 0.5 -hour postdose in the hot-plate latency assay, but in the modified Irwin test, also measured at 0.5 hour postdose, oxycodone showed CNS-mediated behavioral effects starting at $1.0 \mathrm{mg} / \mathrm{kg}$. These data indicate that NKTR-181 has an improved therapeutic ratio for CNS adverse effects in mice compared with oxycodone. Despite higher peripheral exposures of NKTR-181, inhibition of gastrointestinal transit in mice was comparable to that observed with equianalgesic doses of oxycodone.

Consistent with our hypothesis, self-administered NKTR-181 did not produce any significant reinforcing effects even at concentrations exceeding 500-fold (molar equivalents) over those concentrations of oxycodone that maintained stable selfadministration behavior. This was also reflected in the progressive-ratio "break points" study (measuring the relative work an animal was willing to exert to receive NKTR-181) in which NKTR-181 showed predominantly low progressiveratio break points similar to saline, even at concentrations exceeding 170-fold (molar equivalents) those for oxycodone. These data demonstrate that NKTR-181 has reduced abuse potential in rats compared with oxycodone.

In understanding the abuse liability of the mu-agonist class of opioid drugs, it is important to consider the critical relationship between signal transduction through the MOR, which by inhibiting GABAergic interneurons in the ventral tegmental area increases dopamine release and activity of dopamineresponsive neurons in the reward centers (e.g., nucleus accumbens) of the CNS. Although we did not measure MOR occupancy or rate of dopamine release in this study, it is reasonable to speculate from the results of our behavioral data that the inherent PK properties of NKTR-181 may reduce its downstream effects on MOR occupancy and dopamine activity relative to traditional opioids. The consequence is that there is a reduction of the abuse potential of NKTR-181 and significant overall improvement of its pharmaceutical profile compared with traditional opioids. That these effects are influenced primarily by kinetic considerations is evidenced by the equivalent maximal analgesic efficacy of NKTR-181 and oxycodone.

The data we have presented here are from analgesic and behavioral studies that were conducted only on male animals. However, it has been reported in both animals and humans that the analgesic potency of opioids is affected by sex and 

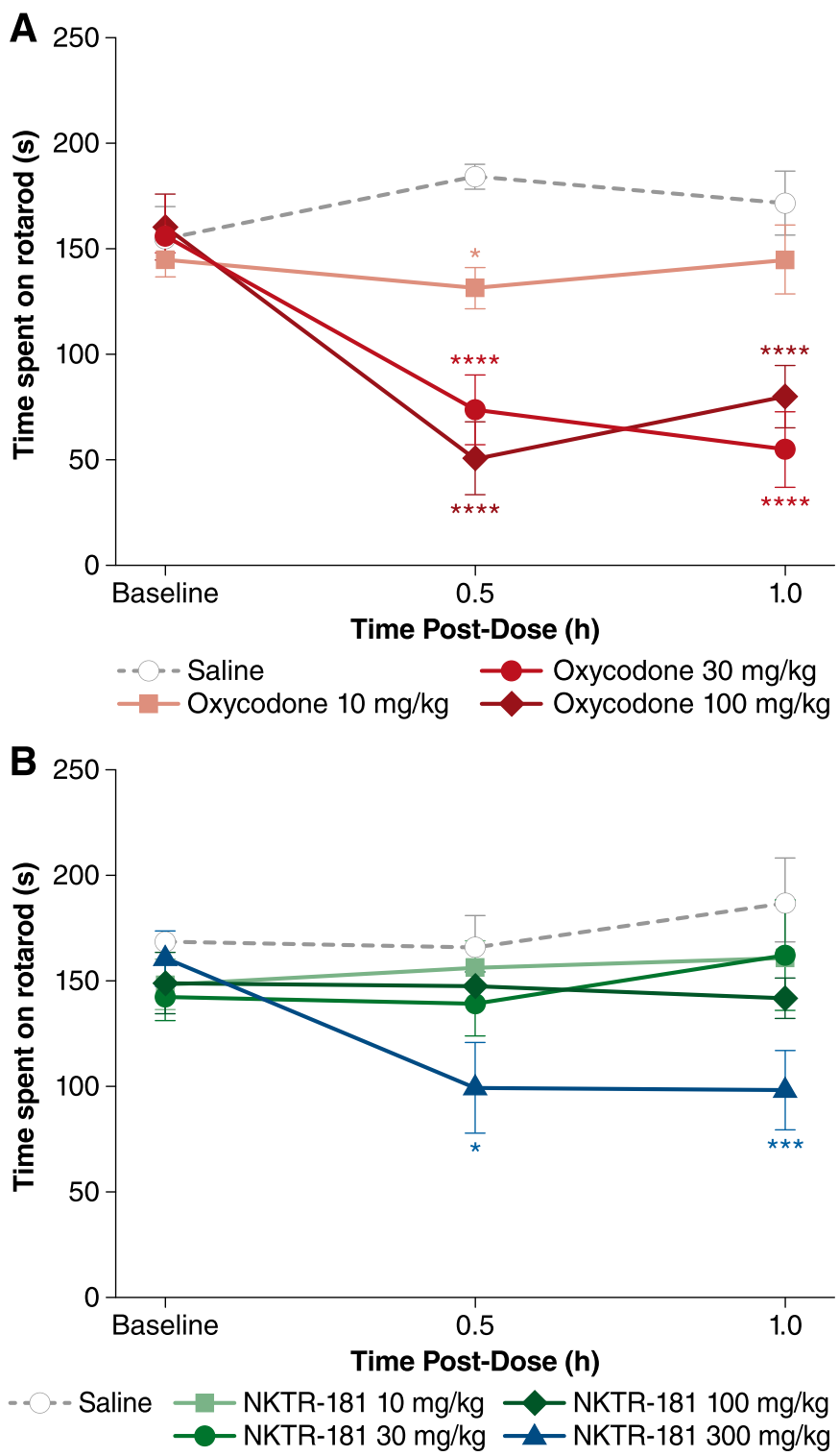

Fig. 6. Effect of orally administered oxycodone (A) and NKTR-181 (B) on motor coordination in rats. Oxycodone and NKTR-181 were evaluated using the rotarod test at baseline (prior to dose) and 0.5 and 1 hour postdose. Duration of running was measured as time spent on the rotarod (seconds). Data represent mean \pm S.E.M. values $(n=5)$. Statistical significance determined with two-way ANOVA, Bonferroni post-test with respect to saline $(* P<0.05 ; * * * P<0.001 ; * * * * P<0.0001)$. Ratio of molar equivalent doses for NKTR-181 to oxycodone is 1.8 to 1 . Molar conversions of doses tested are as follows: $10(28 \mu \mathrm{mol} / \mathrm{kg}$ oxycodone, $16 \mu \mathrm{mol} / \mathrm{kg}$ NKTR-181), $30 \quad(85 \mu \mathrm{mol} / \mathrm{kg}$ oxycodone, $47 \mu \mathrm{mol} / \mathrm{kg}$ NKTR-181), $100(280 \mu \mathrm{mol} / \mathrm{kg}$ oxycodone, $160 \mu \mathrm{mol} / \mathrm{kg}$ NKTR-181), and $300 \mathrm{mg} / \mathrm{kg}$ (470 $\mu \mathrm{mol} / \mathrm{kg}$ NKTR-181); $n=10$ /group.

gender (Kest et al., 2000). Therefore, further evaluation of female animals would need to be conducted to generalize these data for all animals (Greenspan et al., 2007). Most importantly, these preclinical data for NKTR-181 have translated well in the clinic for both men and women. Thus, phase 1 and human abuse potential studies showed slower onset of CNS effects, e.g., miosis (comparing times between peak plasma concentration and maximal pupil constriction) and minimal drug likability (Webster et al., 2017). Furthermore, analgesic efficacy characteristic of long-acting mu-opioid agonists was
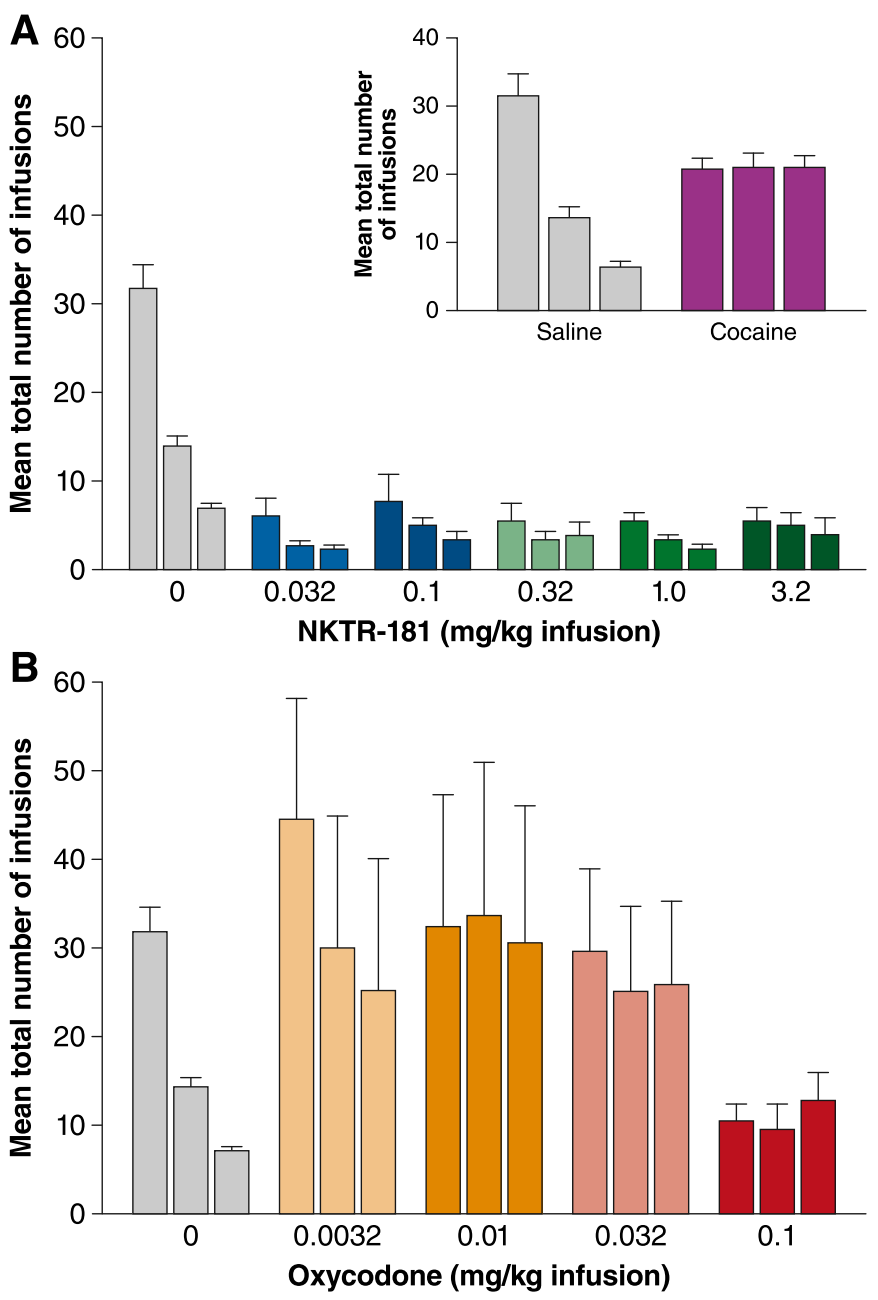

Fig. 7. Three-day substitution test with NKTR-181 (A) or oxycodone (B). NKTR-181 showed no positive reinforcing effects in the 3-day substitution test in rats, whereas oxycodone showed increasing reinforcing effects with increasing concentrations, which was reduced at highest concentrations. Bars represent the group means of total session infusions earned during the sequence of 3-day substitution tests conducted with the indicated unit doses of NKTR-181. Each bar represents the mean of six rats per group. Inset graph in (A) shows stable cocaine reinforcing behavior compared with saline. Ratio of molar equivalent doses for NKTR-181 to oxycodone is 1.8 to 1. Molar conversions of doses tested are as follows: 0.0032 $(9.1 \mathrm{nmol} / \mathrm{kg}$ oxycodone $), 0.01(28 \mathrm{nmol} / \mathrm{kg}$ oxycodone $), 0.032(91 \mathrm{nmol} / \mathrm{kg}$ oxycodone, $51 \mathrm{nmol} / \mathrm{kg}$ NKTR-181), 0.1 (280 nmol/kg oxycodone, $160 \mathrm{nmol} / \mathrm{kg}$ NKTR-181), 0.32 (510 nmol/kg NKTR-181), 1.0 (1582 nmol/kg NKTR-181), and $3.2 \mathrm{mg} / \mathrm{kg}$ (5100 nmol/kg NKTR-181).

recently demonstrated by NKTR-181 in a pivotal human study of chronic low-back pain (Markman J, manuscript in preparation).

In summary, we have demonstrated that NKTR-181 is a long-acting, selective mu-opioid agonist with analgesic efficacy comparable to that of oxycodone, but with a significantly reduced rate of CNS uptake, independent of gut absorption rate. Significantly reduced effects on drug reinforcement and abuse potential were consistent with growing scientific evidence suggesting that rates of CNS uptake and reinforcement behavior contribute to drug addiction. NKTR-181 represents the first example of an effective opioid analgesic with substantially reduced abuse liability due to reduced rate of CNS uptake, which is entirely dependent on its inherent structural properties, rather than extended-release ADF. 


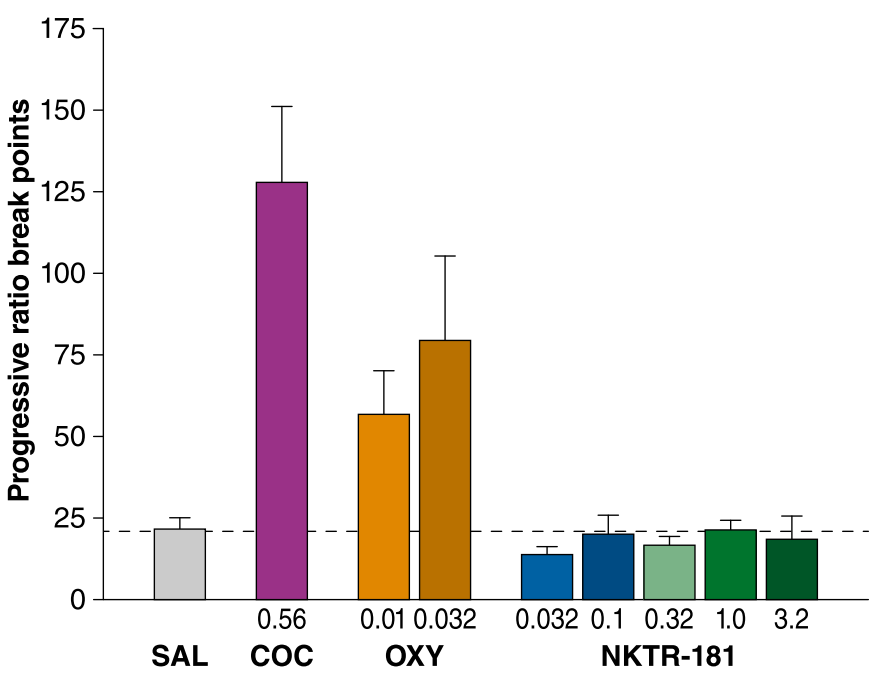

Fig. 8. NKTR-181 displays behavior comparable to saline in the progressive-ratio break point study. Doses of infusion were as follows: cocaine (COC) $(0.56 \mathrm{mg} / \mathrm{kg} /$ infusion ), oxycodone (OXY) $(0.01$ and $0.032 \mathrm{mg} / \mathrm{kg} / \mathrm{infu}-$ sion), and NKTR-181 (0.032, 0.1, 0.32, 1.0 , and $3.2 \mathrm{mg} / \mathrm{kg} / \mathrm{infusion})$. Values are expressed as mean \pm S.E.M. Ratio of molar equivalent doses for NKTR-181 to oxycodone is 1.8 to 1 . Molar conversions of doses tested are as follows: $0.01(28 \mathrm{nmol} / \mathrm{kg}$ oxycodone $), 0.032(91 \mathrm{nmol} / \mathrm{kg}$ oxycodone, $51 \mathrm{nmol} / \mathrm{kg}$ NKTR-181), 0.1 (160 nmol/kg NKTR-181), $0.32(510 \mathrm{nmol} / \mathrm{kg}$ NKTR-181), 1.0 (1582 nmol/kg NKTR-181), and $3.2 \mathrm{mg} / \mathrm{kg}(5100 \mathrm{nmol} / \mathrm{kg}$ NKTR-181).

\section{Acknowledgments}

In vitro opioid receptor function assays were conducted at Albany Molecular Research Institute (Bothell, WA). In situ brain perfusion studies were conducted at Absorption Systems, LP. Rat selfadministration and drug discrimination studies were conducted at MPI Research, Inc. Remaining studies were conducted by Nektar Therapeutics, Preclinical Pharmacology, and ADME PK groups. We thank Allan I. Basbaum, FRS, Chair of Anatomy at the University of California, San Francisco, and Martin E. Hale of Gold Coast Research, LLC, for reviewing this manuscript and providing valuable input. We thank Linnéa Elliott and The Curry Rockefeller Group, LLC, for expert medical editing assistance.

\section{Authorship Contributions}

Participated in research design: Choi, Evans, Gursahani, Pfeiffer, Gauvin, Riley, Riggs, Gogas, Doberstein.

Conducted experiments: Choi, Ali, Evans, Gursahani, Hennessy, Kim, McWeeney, Pfeiffer, Quach, Gauvin, Gogas.

Contributed new reagents or analytic tools: Pfeiffer, Riley, Riggs.

Performed data analysis: Choi, Rubas, Ali, Gursahani, Hennessy,

Kim, Pfeiffer, Quach, Gauvin, Riley, Riggs, Gogas.

Wrote or contributed to the writing of the manuscript: Miyazaki, Choi, Rubas, Anand, Evans, Pfeiffer, Gauvin, Riggs, Gogas, Zalevsky, Doberstein.

\section{References}

Abreu ME, Bigelow GE, Fleisher L, and Walsh SL (2001) Effect of intravenous injection speed on responses to cocaine and hydromorphone in humans. Psychopharmacology (Berl) 154:76-84

Bui K, She F, Zhou D, Butler K, Al-Huniti N, and Sostek M (2016a) The effect of quinidine, a strong P-glycoprotein inhibitor, on the pharmacokinetics and central nervous system distribution of naloxegol. J Clin Pharmacol 56:497-505.

Bui K, Zhou D, Sostek M, She F, and Al-Huniti N (2016b) Effects of CYP3A modulators on the pharmacokinetics of naloxegol. J Clin Pharmacol 56:1019-1027.

Cheng Y and Prusoff WH (1973) Relationship between the inhibition constant (K1) and the concentration of inhibitor which causes 50 per cent inhibition (I50) of an enzymatic reaction. Biochem Pharmacol 22:3099-3108.
Comer SD, Ashworth JB, Sullivan MA, Vosburg SK, Saccone PA, and Foltin RW (2009) Relationship between rate of infusion and reinforcing strength of oxycodone in humans. J Opioid Manag 5:203-212.

Cone EJ, Giordano J, and Weingarten B (2013) An iterative model for in vitro laboratory assessment of tamper deterrent formulations. Drug Alcohol Depend 131: $100-105$.

Corsetti $\mathrm{M}$ and Tack $\mathrm{J}$ (2015) Naloxegol: the first orally administered, peripherally acting, mu opioid receptor antagonist, approved for the treatment of opioid-induced constipation. Drugs Today (Barc) 51:479-489.

Dickenson AH and Kieffer B (2005) Opiates-basic, in Wall and Melzack's Textbook of Pain, 5th ed (McMahon A and Koltzenburg M, eds) pp 427-442, Elsevier Health Sciences, New York.

Farré M and Camí J (1991) Pharmacokinetic considerations in abuse liability evaluation. Br J Addict 86:1601-1606.

Gauvin DV, McComb M, Code R, Dalton JA, and Baird TJ (2015) Abuse liability assessment of hydrocodone under current draft regulatory guidelines. $J$ Pharmacol Toxicol Methods 75:118-129.

Greenspan JD, Craft RM, LeResche L, Arendt-Nielsen L, Berkley KJ, Fillingim RB, Gold MS, Holdcroft A, Lautenbacher S, Mayer EA, et al.; Consensus Working Group of the Sex, Gender, and Pain SIG of the IASP (2007) Studying sex and gender differences in pain and analgesia: a consensus report. Pain 132 (Suppl 1): S26-S45.

Inturrisi CE (2002) Clinical pharmacology of opioids for pain. Clin J Pain 18 (4, Suppl):S3-S13.

Kest B, Sarton E, and Dahan A (2000) Gender differences in opioid-mediated analgesia: animal and human studies. Anesthesiology 93:539-547.

Leslie FM (1987) Methods used for the study of opioid receptors. Pharmacol Rev 39:197-249.

Manchikanti L, Helm S, II, Fellows B, Janata JW, Pampati V, Grider JS, and Boswell MV (2012) Opioid epidemic in the United States. Pain Physician 15(3, Suppl): ES9-ES38.

Marsch LA, Bickel WK, Badger GJ, Rathmell JP, Swedberg MD, Jonzon B, and Norsten-Höög C (2001) Effects of infusion rate of intravenously administered morphine on physiological, psychomotor, and self-reported measures in humans. J Pharmacol Exp Ther 299:1056-1065.

McKinney M and Raddatz R (2006) Unit 1.3: practical aspects of radioligand binding, in Current Protocols in Pharmacology (Enna SJ, Williams M, Kenakin T, McGonigle P, Ruggeri B, and Wickenden AD, eds) John Wiley and Sons, Inc., New York. Melnikova I (2010) Pain market. Nat Rev Drug Discov 9:589-590.

Milligan G and Kostenis E (2006) Heterotrimeric G-proteins: a short history. $\mathrm{Br}$ $J$ Pharmacol 147 (Suppl 1):S46-S55.

Motulsky H and Christopoulos A (2004) Fitting Models to Biological Data Using Linear and Nonlinear Regression: A Practical Guide to Curve Fitting, Oxford University Press, New York.

Panlilio LV and Goldberg SR (2007) Self-administration of drugs in animals and humans as a model and an investigative tool. Addiction 102:1863-1870.

Raffa RB, Pergolizzi JV, Jr, Muñiz E, Taylor R, Jr, and Pergolizzi J (2012) Designing opioids that deter abuse. Pain Res Treat 2012:282981.

Roux S, Sablé E, and Porsolt RD (2005) Primary observation (Irwin) test in rodents for assessing acute toxicity of a test agent and its effects on behavior and physiological function, in Current Protocols in Pharmacology (Enna SJ, Williams M, Kenakin T, McGonigle P, Ruggeri B, and Wickenden AD, eds John Wiley and Sons, Inc., New York.

Rudd RA, Aleshire N, Zibbell JE, and Gladden RM (2016) Increases in drug and opioid overdose deaths-United States, 2000-2014. MMWR Morb Mortal Wkly Rep 64 (50-51):1378-1382.

Seamon KB, Padgett W, and Daly JW (1981) Forskolin: unique diterpene activator of adenylate cyclase in membranes and in intact cells. Proc Natl Acad Sci USA 78: 3363-3367.

Spetea M, Bohotin CR, Asim MF, Stübegger K, and Schmidhammer H (2010) In vitro and in vivo pharmacological profile of the 5-benzyl analogue of 14 methoxymetopon, a novel mu opioid analgesic with reduced propensity to alter motor function. Eur J Pharm Sci 41:125-135.

U.S. Food and Drug Administration (2015) Guidance for Industry: Abuse-Deterrent Opioids - Evaluation and Labeling, US Food and Drug Administration, Silver Spring, MD. https://www.fda.gov/downloads/drugs/guidancecomplianceregulatoryinformation/guidances/ucm334743.pdf

Webster LR, Bath B, Medve RA, Marmon T, and Stoddard GJ (2012) Randomized, double-blind, placebo-controlled study of the abuse potential of different formulations of oral oxycodone. Pain Med 13:790-801.

Webster L, Henningfield J, Buchhalter AR, Siddhanti S, Lu L, Odinecs A, Di Fonzo CJ, and Eldon MA (2017) Human abuse potential of the new opioid analgesic molecule NKTR-181 compared with oxycodone. Pain Med DOI: 10.1093/pm/ pnw344

Webster LR and Smith MD (2015) Abuse quotient: an essential measure of opioid analgesic human abuse potential (HAP). Drug Alcohol Depend 156:e235-e236.

Whiteside GT, Adedoyin A, and Leventhal L (2008) Predictive validity of animal pain models? A comparison of the pharmacokinetic-pharmacodynamic relationship for pain drugs in rats and humans. Neuropharmacology 54:767-775.

Address correspondence to: Dr. Stephen K. Doberstein, Nektar Therapeutics, 455 Mission Bay Blvd. South, San Francisco, CA 94158. E-mail: sdoberstein@nektar.com 